\title{
VARIABILIDADE DOS ATRIBUTOS FÍSICOS DO SOLO E DINÂMICA DA PALHADA EM SISTEMA INTEGRAÇÃO LAVOURA-PECUÁRIA NO CERRADO
}

\author{
ALESSANDRO GUERRA DA SILVA ${ }^{1}$, RENATO LARA DE ASSIS ${ }^{2}$, \\ CARLOS ALBERTO ALVES DE OLIVEIRA ${ }^{3}$, CAMILA JORGE BERNABÉ FERREIRA ${ }^{1}$, \\ ITAMAR ROSA TEIXEIRA ${ }^{4}$, KEULY DE LOLLO ALMEIDA ${ }^{1}$ e EDUARDO LIMA DO CARMO ${ }^{1}$
}

\author{
${ }^{1}$ Universidadede Rio Verde,Rio Verde,GO,Brasil.E-mail:silvaag@yahoo.com.br,camilajbferreira@gmail.com keuly@uol.com.br \\ 2Instituto Federal Goiano, Campus Iporá,Iporá, GO,Brasil, relassis@bol.com.br, eduardo@unirv.edu.br \\ ${ }^{3}$ Instituto Federal do Triângulo Mineiro, Campus Uberlândia, Uberlândia, MG, Brasil, carlosoliveira@iftm.edu.br \\ ${ }^{4}$ Universidade Estadual de Goiás, Anápolis, GO,Brasil, itamar.texeira@ueg.br
}

Revista Brasileira de Milho e Sorgo, v.18, n.3, p. 429-440, 2019

\begin{abstract}
RESUMO - O consórcio milho e braquiária vem aumentando cada vez mais na região Centro-Oeste do Brasil, contudo os efeitos sobre a qualidade física do solo e a dinâmica da decomposição da palhada ainda são pouco conhecidos. $\mathrm{O}$ objetivo deste trabalho foi avaliar a variabilidade temporal dos atributos físicos do solo e a dinâmica da palhada em sistema integração lavoura-pecuária com soja no verão e milho+braquiária e pastagem em safrinha na região CentroOeste. O trabalho foi conduzido no município de Montividiu-GO com o consórcio de milho e Brachiaria brizantha em área de 200 ha. Após a colheita do milho, no final de julho, liberou-se a entrada de 155 bovinos, sendo os mesmos retirados noventa dias após a entrada, no final de outubro. Antes, durante e após o pastejo, foram avaliados resistência do solo à penetração, densidade do solo, macro e microporosidade e porosidade total nas camadas de $0,0-0,1 ; 0,1-0,2$; 0,2-0,3; e 0,3-0,4 m, bem como biomassa seca do milho, braquiária e biomassa total. Avaliou-se também cobertura do solo e relação $\mathrm{C} / \mathrm{N}$ do milho e braquiária. Os resultados permitiram concluir que o pisoteio ocasionado pelos animais em pastejo, com baixa taxa de lotação, não alteraram a qualidade física do solo na área de sistema de integração lavourapecuária (SILP). Além disso, esse sistema permitiu a intensificação econômica da área com agregação de uma terceira safra de carne (com forragem suficiente para produzir 1,16@ carne ha ${ }^{-1}$ ) além de contribuir para melhoria da qualidade do sistema de plantio direto mediante acréscimo de cobertura vegetal do solo, mesmo sob condições de pastejo. Palavras-chave: Brachiaria brizantha, densidade do solo, resistência do solo à penetração, Zea mays.
\end{abstract}

\section{VARIABILITY OF THE SOIL PHYSICAL ATTRIBUTES AND STRAW DYNAMICS IN CROP-LIVESTOCK INTEGRATION SYSTEM IN THE BRAZILIAN SAVANNA}

\begin{abstract}
The maize and brachiaria consortium has increased in the Midwest region of Brazil, however the effects on soil physical quality and the dynamics of straw decomposition are still poorly understood. In this sense, the objective of this work was to evaluate the temporal variability of soil physical attributes and straw dynamics in a crop-livestock integration system. The work was carried out in Montividiu, Goiás state in central-west region of Brazil with the consortium of maize and Brachiaria brizantha in succession to soybean in an area of $200 \mathrm{ha}$. After the maize harvest at the end of July, 155 cattleentered the area, being removed at the end of October. Before, during and after grazing, soil penetration resistance, soil bulk density, macro and microporosity and total porosity in the soil layer of $0.0-0.1 ; 0.1-0.2$; 0.2-0.3; and 0.3-0.4 m, as well as dry biomass of maize, brachiaria and total biomass were evaluated. Soil cover and $\mathrm{C} / \mathrm{N}$ ratio of maize and brachiaria were also evaluated. The results allowed to conclude that the trampling caused by grazing animals, with low stocking rate, did not alter the soil physical quality in the crop-livestock integration system (SILP). In addition, this system allowed the economic intensification of the area with the aggregation of a third crop of meat (with sufficient forage to produce1.16@ meat ha ${ }^{-1}$ ) while contributing to improved quality of the no-till system by addition soil cover even under grazing conditions.
\end{abstract}

Keywords: Zea mays, Brachiaria brizantha, soil bulk density, penetration resistance. 
Uma das grandes preocupações em áreas de pastagem em relação a sua longevidade e sustentabilidade está relacionada a perda da qualidade física do solo que pode comprometer a produtividade da pastagem (Moreira et al., 2012). Neste contexto, a redução da qualidade física do solo está principalmente relacionada à pressão de pastejo exercida pelo pisoteio animal (Petean et al., 2010; Fidalski et al., 2013).

O manejo incorreto das pastagens pode promover um efeito deletério sobre os atributos físicos do solo, principalmente na camada superficial do solo, comprometendo o crescimento das raízes (Beloni et al., 2016). Tal efeito é diretamente associado ao aumento da resistência do solo à penetração (Ferreira et al., 2018), aumento da densidade do solo (Veiga et al., 2014) e mudanças no sistema poroso do solo. Além disto, pode ocorrer redução da cobertura vegetal sobre o solo e o aproveitamento de nutrientes pelas culturas devido ao limitado crescimento das raízes (Ferreira et al., 2018).

O sistema de integração lavoura-pecuária (SILP) tem ganhado destaque na agricultura atual por ser considerado um sistema agrícola com vantagens econômicas e sociais. O sistema em questão alterna, em um mesmo ano e área, a utilização de espécies forrageiras que são utilizadas para a alimentação animal com culturas destinadas à produção de grãos (Maia et al., 2014). O SILP combina técnicas que minimizam os custos operacionais e aumentam a sustentabilidade do sistema de produção, promovendo a recuperação de pastagens e melhoria da qualidade física do solo (Flávio Neto et al., 2015), além da melhoria das propriedades biológicas e químicas do solo. Adicionalmente, a utilização do SILP sob sistema plantio direto contribui para uma melhor formação de palhada e conservação do solo (Petter et al., 2011), essencial para a viabilidade do sistema em condições de Cerrado.
O cultivo de espécies forrageiras consorciadas com culturas anuais tem se mostrado uma técnica eficiente e economicamente viável como método de formação, recuperação e renovação de pastagens, com destaque para a utilização do consórcio de milho com espécies do gênero Brachiaria (Flávio Neto et al., 2015). Nas condições do Brasil Central, as gramíneas forrageiras se destacam como alternativa para o consórcio, pois a palhada produzida apresenta alta relação $\mathrm{C} / \mathrm{N}$, com menor velocidade de decomposição e maior tempo de proteção do solo contra a insolação e o impacto das gotas da chuva. Isto resulta, respectivamente, em redução na evaporação de água do solo e na erosão. Além disso, aumenta a eficiência da ciclagem dos nutrientes e auxilia no controle de plantas daninhas (Ikeda et al., 2007).

A vantagem do uso de espécies de braquiárias no SILP está no fato destas espécies apresentarem sistema radicular abundante e profundo, o que contribui para a melhoria da infiltração de água no solo e proporciona melhor agregação e aeração do solo (Flávio Neto et al., 2015). Além disso, essa forragem possui a característica de apresentar boa adaptabilidade, tolerância e resistência a fatores bióticos e apresentar alta produção de matéria seca com elevado valor nutricional, capaz de atender a demanda dos animais, especialmente na estação seca do ano.

Apesar de todas as vantagens que o SILP oferece em lavouras de produção de grãos no Centro-Oeste, muitos produtores ainda têm receio em adotar esse sistema, justificando o fato de que a presença de bovinos possa resultar na compactação do solo. Além disso, ainda persistem questionamentos sobre a qualidade física do solo nos SILP sob plantio direto na região. Assim, com a finalidade de fornecer subsídios para o manejo de SILP sustentáveis, o presente trabalho teve como objetivo avaliar a variabilidade tem- 
poral dos atributos físicos do solo e a dinâmica da palhada em sistema integração lavoura-pecuária em safrinha na região Centro-Oeste.

O estudo foi conduzido na Fazenda Vargem Grande, localizada no município de Montividiu-GO $\left(17^{\circ} 21^{\prime} 45,62^{\prime \prime S} ; 51^{\circ} 28^{\prime} 56,18^{\prime}\right.$ W e altitude média de $957 \mathrm{~m}$ ), em área caracterizada por apresentar relevo plano, com declividade menor que $3 \%$. A precipitação média anual da região é de $1.710 \mathrm{~mm}$, com temperatura média anual de $22,5^{\circ} \mathrm{C}$ e clima do tipo $\mathrm{Aw}$ (clima tropical semi-úmido), segundo classificação de Köppen. Os dados meteorológicos foram disponibilizados pelo Instituto Nacional de Meteorologia (INMET) e estão apresentados na Figura 1 juntamente com o manejo dos animais referentes ao período de estudo.

O solo foi identificado como Latossolo Vermelho Eutroférrico (Santos et al., 2018), de textura argilosa. Antes da implantação da cultura de verão, retirou-se amostras de solo na qual apresentou as seguintes características físicas e químicas: 523, 227 e $251 \mathrm{~g} \mathrm{~kg}^{-1}$ de argila, silte e areia, respectivamente;
$\mathrm{pH}$ em $\mathrm{H}_{2} \mathrm{O}$ de 4,9; 38,0 $\mathrm{g} \mathrm{kg}^{-1}$ de matéria orgânica (Walkley-Black); 20,2 e $20 \mathrm{mg} \mathrm{dm}^{-3}$ de P $\left(\right.$ Mehlich $\left.^{-1}\right)$ e $\mathrm{K}\left(\right.$ Mehlich $\left.^{-1}\right)$, respectivamente; $1,5 \mathrm{cmol}_{\mathrm{c}} \mathrm{dm}^{-3} \mathrm{de}$ $\mathrm{Ca}\left(\mathrm{KCl} \mathrm{mol} \mathrm{L}^{-1}\right) ; 0,5 \mathrm{cmol}_{\mathrm{c}} \mathrm{dm}^{-3}$ de $\mathrm{Mg}\left(\mathrm{KCl} \mathrm{mol} \mathrm{L}^{-1}\right)$; 2,0 $\mathrm{cmol}_{\mathrm{c}} \mathrm{dm}^{-3}$ de soma de bases; $1,3 \mathrm{cmol}_{\mathrm{c}} \mathrm{dm}^{-3} \mathrm{de} \mathrm{Al}$ $\left(\mathrm{KCl} \mathrm{mol} \mathrm{L}{ }^{-1}\right) ; 3,8 \mathrm{cmol}_{\mathrm{c}} \mathrm{dm}^{-3}$ de $\mathrm{H}+\mathrm{Al}(\mathrm{SMP}) ; 5,8$ $\mathrm{cmol}_{\mathrm{c}} \mathrm{dm}^{-3}$ de capacidade de troca catiônica; e $34,5 \%$ de saturação por bases.

O solo da área experimental é cultivado há mais de quinze anos no sistema plantio direto. $\mathrm{Na}$ área, foi adotado o sistema de rotação de culturas sendo cultivado soja (primavera-verão) e milho+braquiária em sucessão (verão-outono) e, no ano seguinte algodão safra (única cultura na mesma safra de verão) e milho e feijão em sucessão (outono). Inicialmente, implantou-se na safra 2005/2006 a variedade de soja MSOY 6101, de ciclo superprecoce, com equivalente a 555.000 plantas ha $^{-1}$ no espaçamento entrelinhas de $0,45 \mathrm{~m}$.

Posteriormente a colheita da soja, foi implantado, de 25 a 28 de janeiro de 2006, o milho consorciado com braquiária no Sistema Santa Fé. Na oca-

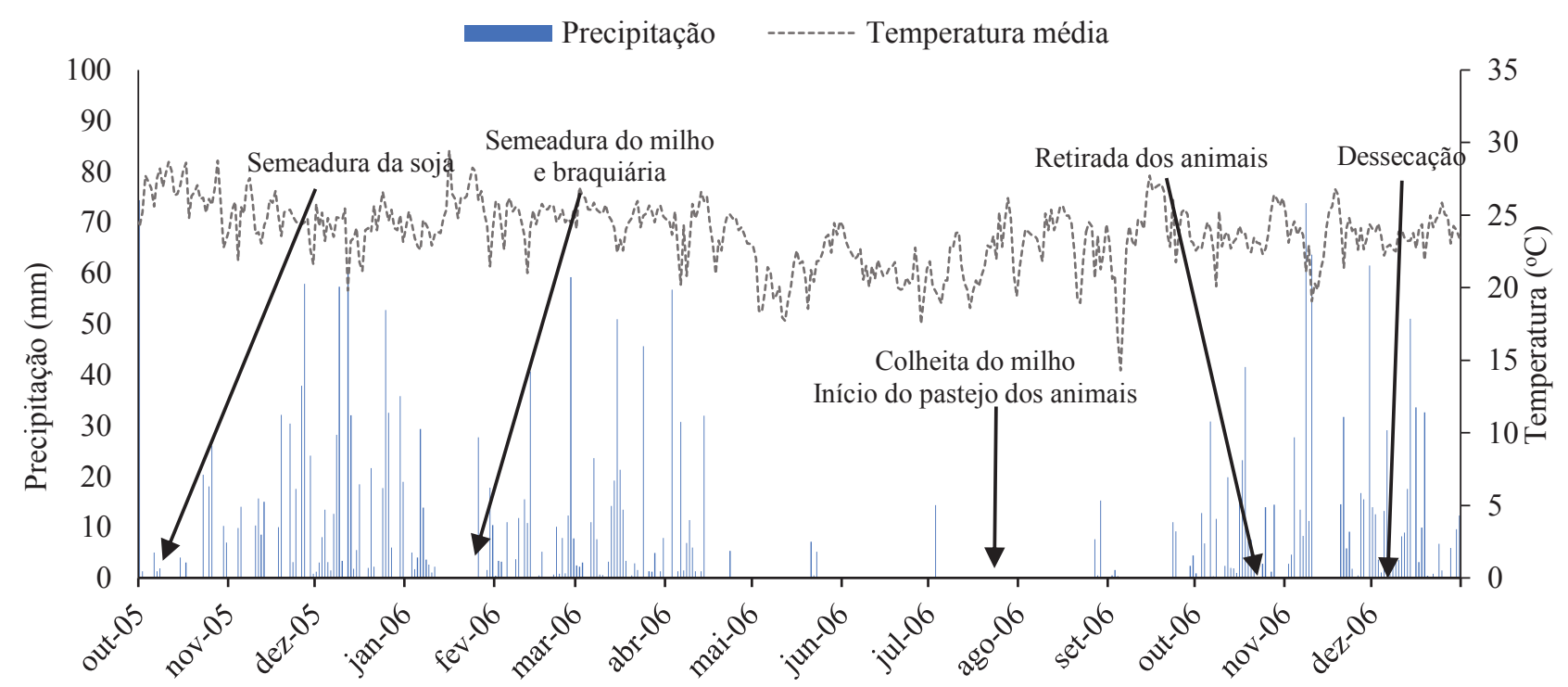

Figura 1. Valores de precipitação e temperatura média na Fazenda Vargem Grande, Montividiu-GO, 2006. 
sião, utilizou-se o híbrido Pointer (híbrido simples, precoce, com grãos duros de cor alaranjada) no espaçamento entrelinhas de 0,90 m. Para a gramínea forrageira consorciada, utilizou-se a espécie Brachiaria brizantha cultivar Marandu, a qual foi semeada simultaneamente nas entrelinhas da cultura do milho, utilizando-se o equivalente a $7,0 \mathrm{~kg} \mathrm{ha}^{-1}$ de sementes. No consórcio, somente a cultura do milho foi adubada com o equivalente a $283 \mathrm{~kg} \mathrm{ha}^{-1}$ de fertilizante da fórmula 09-15-15 + 0,3\% de boro. Na fertilização em cobertura, aos 25 dias após a emergência das plântulas de milho utilizou-se $80 \mathrm{~kg} \mathrm{ha}^{-1}$ de $\mathrm{N}$ na forma de ureia, aplicada de forma mecanizada a lanço.

A colheita do milho foi realizada em 26 de julho. No dia seguinte, efetuou-se a liberação de cento e cinquenta e cinco bovinos, com peso médio de doze arrobas por animal $\left(0,62 \mathrm{UA} \mathrm{ha}^{-1}\right)$, considerando-se a unidade animal $(\mathrm{UA})=450 \mathrm{~kg}$. Estes permaneceram no talhão por um período de três meses, além de receber suplementação mineral. Em 25 de outubro, os animais foram retirados do pasto e pesados individualmente para análise do ganho de massa. A análise dos efeitos do pastejo dos animais sobre os atributos físicos do solo, na dinâmica de decomposição da palhada do milho e no crescimento da braquiária no período da entressafra, foram determinados a partir de cinco pontos georreferenciados para a coleta de amostras.

Uma das avaliações realizadas foi a resistência à penetração $(\mathrm{RP})$. Estas foram realizadas em quatro épocas de avaliações: antes da entrada dos animais logo após a colheita do milho (26 de julho), 24 e 59 dias após a entrada dos mesmos (19 de agosto e 23 de setembro), e após a retirada dos animais (02 de novembro). Nessa avaliação, utilizou-se um penetrômetro de impacto, determinando o número de impactos por centímetro (Stolf, 1991) nas camadas de 0,0 a 0,$1 ; 0,1$ a $0,2,0,2$ a 0,3 e de 0,3 a $0,4 \mathrm{~m}$ em cinco repetições por ponto georreferenciado.

Para o cálculo da resistência à penetração, o número de impactos foi transformado em resistência dinâmica $(\mathrm{MPa})$ por meio da equação proposta por Stolf (1991), ou seja, RP $\left(\mathrm{kgf} \mathrm{cm} \mathrm{cm}^{-2}\right)=5,6+6,89 . \mathrm{N}$ (impactos $\mathrm{dm}^{-1}$ ). Para proceder a conversão da resistência à penetração em $\mathrm{kgf} \mathrm{cm}^{-2}$ para $\mathrm{MPa}$, multiplicou-se o valor obtido pela constante 0,098 . Também foram coletadas amostras para determinação da umidade do solo (anéis volumétricos de $100 \mathrm{~cm}^{3}$ ) em cada ponto e camada amostrada ( 0,0 a 0,$1 ; 01$, a 0,2 ; e 0,2 a $0,4 \mathrm{~m}$ ) para determinação da resistência à penetração, as quais foram secas em estufa a $105^{\circ} \mathrm{C}$ por $24 \mathrm{~h}$. Posteriormente, a umidade do solo foi obtida pela razão entre a massa de água e a massa de sólidos do solo.

Em 26 de julho e 02 de novembro, antes e após, respectivamente, a entrada e retirada dos animais na área experimental, foram coletadas amostras indeformadas utilizando-se anéis volumétricos de $100 \mathrm{~cm}^{3}$ $(0,05 \times 0,05 \mathrm{~m}$ de altura e diâmetro, respectivamente) para determinação da densidade do solo, macro e microporosidade e porosidade total no centro das camadas de $0,0-0,1 ; 0,1-0,2 ; 0,2-0,3$; e de $0,3-0,4 \mathrm{~m}$, com três repetições por ponto georreferenciado. $\mathrm{O}$ preparo das amostras consistiu na retirada do excesso de solo das extremidades de cada anel, de modo que o volume do solo fosse equivalente ao volume do anel. Em seguida, essas amostras foram saturadas com água por capilaridade por 48 h. Após a saturação, foi determinada a massa das amostras e submetidas aos potenciais de $-6 \mathrm{kPa}$, utilizando uma mesa de tensão. Ao atingir o equilíbrio, indicado pela ausência de drenagem de água na mesa de tensão, novamente foi determinada a massa das amostras. Posteriormente, as amostras foram secas em estufa a $\pm 105^{\circ} \mathrm{C}$ por 24 $\mathrm{h}$ e novamente foi determinada sua massa. A macro 
e microporosidade, porosidade total e densidade do solo foram determinadas em acordo com metodologia da Embrapa (Donagema et al., 2011).

$\mathrm{Na}$ avaliação da dinâmica de decomposição da palhada de milho e braquiária, foram efetuadas determinações da porcentagem de cobertura do solo, produção de biomassa seca de milho, da braquiária e da biomassa total, além da relação $\mathrm{C} / \mathrm{N}$ de cada espécie. As avaliações foram feitas antes da entrada dos animais, em 26 de julho, aos 24 e 59 dias após a entrada dos animais na área experimental, em 19 de agosto e 23 de setembro, respectivamente, e após a retirada dos animais, em 02 de novembro e 02 de dezembro. Nestas épocas, quantificou-se também a relação da proporcão de biomassa de cada espécie.

Para a determinação da porcentagem da cobertura do solo, foi utilizado um quadrado de ferro, composto de uma linha transversal contendo dez marcações distanciadas de $0,05 \mathrm{~m}$ entre si. Este instrumento foi posicionado, aleatoriamente, em cinco repetições por ponto georreferenciado, observando a presença de palhada sob as marcações na linha, contabilizando desta forma a porcentagem de cobertura do solo.

A biomassa seca disponível foi avaliada a partir de coletas isoladas de amostras das palhadas de milho e braquiária em cinco repetições por ponto georreferenciado, utilizando um quadrado de ferro de dimensões de 0,25 x 0,25 m. Nesta avaliação foram retiradas amostras de toda a parte aérea das plantas (milho e braquiária), efetuando corte rente ao solo, quando necessário. No laboratório separou-se, em cada amostra, a biomassa de milho e da braquiária, sendo posteriormente levadas à estufa com circulação forçada de ar a $65^{\circ} \mathrm{C}$ durante $72 \mathrm{~h}$, para a determinação da biomassa seca e posterior transformação em $\mathrm{kg} \mathrm{ha}^{-}$ 1. As avaliações da relação carbono/nitrogênio $(\mathrm{C} / \mathrm{N})$ das espécies forrageiras foram realizadas utilizando as amostras de biomassa seca de milho e braquiária. Após a moagem das amostras, foram determinados, no material vegetal, os teores de $\mathrm{C}$, a partir da queima em mufla à temperatura de $550^{\circ} \mathrm{C}$ (Donagema et al., 2011), enquanto que o $\mathrm{N}$ foi determinado segundo método descrito por Malavolta et al. (1997).

As comparações dos atributos físicos do solo foram feitas por meio do uso do intervalo de confiança da média a 95\% $(\mathrm{p}<0,05)$ conforme Payton et al. (2000). Consideram-se diferenças estatísticas quando não há sobreposição dos limites superior e inferior dos intervalos de confiança das médias dos tratamentos. Para a produção de biomassa seca do milho e da braquiária e também para a cobertura do solo, as médias de cada avaliação foram comparadas por meio de análise de regressão, bem como a relação $\mathrm{C} / \mathrm{N}$ de ambas as espécie, quando constatada significância para cada variável. Ao final do ensaio a biomassa remanescente de braquiária foi dessecada para implantação da cultura do algodoeiro no início de dezembro.

A partir dos resultados obtidos, constatou-se que o sistema de integração lavoura-pecuária proporcionou a obtenção de produtividade média do milho de $6,9 \mathrm{t} \mathrm{ha}^{-1}$, produtividade considerada satisfatória para o cultivo de milho safrinha, conforme atestado por Oliveira et al. (2017). Após o pastejo na área, constatou-se também que a média de peso vivo, para cada animal, foi de quinze arrobas $\left(0,78 \mathrm{UA} \mathrm{ha}^{-1}\right)$. Consequentemente, houve um ganho de 232,5@de carne, ou seja,1,16@ de carne/ha em três meses. Durante o período em que os animais permaneceram na área. Os resultados obtidos corroboram com os de Canesin et al. (2007) que observaram ganho de peso animal semelhante com o uso de $B$. brizantha na estação seca do ano. Este resultado demonstra o potencial que a utilização do consórcio milho e braquiária representam para a engorda dos animais na entressa- 
fra no Centro-Oeste, agregando renda ao produtor de grãos da região.

Apesar da camada superficial do solo ser a mais modificada pelo impacto do pisoteio animal, a mesma foi a que apresentou os menores valores de resistência à penetração, independente da época de avaliação (Tabela 1). Isto indica que a cobertura vegetal no SILP minimizou o efeito do pisoteio animal sobre a camada superficial do solo, cuja degradação tem sido relacionada à redução da cobertura vegetal (Ferreira et al., 2010). Além disso, a alta concentração de raízes na camada superficial do solo supostamente contribuiu para os baixos valores de resistência à penetração na referida camada corroborando dados de Ferreira et al. (2018).

De forma geral, para todas as camadas avaliadas, os menores valores de resistência à penetração foram verificados em 02 de novembro (Tabela 1). Esta época coincide com aquela em que se observou os maiores valores de umidade do solo em relação às demais. É oportuno destacar que uma pequena variação na umidade do solo é suficiente para promover mudanças nos valores de resistência à penetração
(Moreira et al., 2012). Isto é atribuído ao fato de que a água atua como um "lubrificante" natural entre as partículas do solo, diminuindo a força de coesão, reduzindo consequentemente a resistência à penetração (Almeida et al., 2012).

Ressalta-se que valores de resistência à penetração acima de 2,5 Mpa, independente da umidade do solo, é considerado restritivo ao crescimento das raízes de gramíneas, conforme atestado por Imhoff et al. (2000). Apesar de ser observado em todas as épocas de avaliação valores acima do restritivo, esse fato é atribuído a baixa umidade do solo nas épocas avaliadas.

No entanto, um solo é considerado compactado somente quando apresenta valores de resistência à penetração acima do valor considerado restritivo e quando a umidade está próxima aos valores de capacidade de campo (Imhoff et al., 2000). Na mesma área de estudo, Assis et al. (2013) observaram valor de umidade na capacidade de campo em torno de $26 \%$, ou seja, umidade bem acima das observadas no presente estudo. Isto leva a crer que independente da época de avaliação, a umidade do solo se encontrava

Tabela 1. Valores médios de resistência do solo à penetração e umidade do solo em função das épocas e camadas de avaliação. Montividiu-GO. 2006.

\begin{tabular}{cccccc}
\hline \multirow{2}{*}{ Camada $(\mathrm{m})$} & 26 de julho & \multicolumn{4}{c}{ Épocas de avaliação } \\
& \multicolumn{7}{c}{--- Resistência do solo à penetração (MPa) } & --- & \multirow{2}{*}{ Médias } \\
\hline 0,0 a 0,1 & $2,50 \pm 0,57$ & $2,47 \pm 0,43$ & $3,21 \pm 0,50$ & $1,60 \pm 0,32$ & 2,44 \\
0,1 a 0,2 & $4,10 \pm 0,30$ & $4,20 \pm 0,40$ & $4,57 \pm 0,65$ & $2,10 \pm 0,27$ & 3,74 \\
0,2 a 0,3 & $5,00 \pm 0,42$ & $5,25 \pm 0,89$ & $5,61 \pm 0,65$ & $2,65 \pm 0,45$ & 4,62 \\
0,3 a 0,4 & $5,40 \pm 0,43$ & $5,96 \pm 0,61$ & $6,18 \pm 0,33$ & $3,06 \pm 0,40$ & 5,15 \\
Médias & $4,25 \pm 0,43$ & $4,47 \pm 0,58$ & $4,89 \pm 0,53$ & $2,35 \pm 0,36$ & 3,99 \\
\hline \multicolumn{7}{c}{--- Umidade $(\%)---$} \\
0,0 a 0,1 & $10,23 \pm 0,89$ & $11,34 \pm 1,30$ & $8,57 \pm 0,82$ & $17,48 \pm 2,71$ & 11,90 \\
0,1 a 0,2 & $12,93 \pm 2,11$ & $12,09 \pm 2,32$ & $10,23 \pm 1,40$ & $19,73 \pm 3,02$ & 13,74 \\
0,2 a 0,4 & $13,27 \pm 2,01$ & $13,69 \pm 2,07$ & $10,30 \pm 1,22$ & $17,48 \pm 2,33$ & 13,68 \\
Médias & $12,14 \pm 1,97$ & $12,37 \pm 1,94$ & $9,70 \pm 0,76$ & $18,23 \pm 2,59$ & 13,11 \\
\hline
\end{tabular}

*A sobreposição dos intervalos de confiança indica ausência de diferenças entre as médias ( $\mathrm{p}>0,05)$. 
abaixo da capacidade de campo, não sendo possível inferir com essa variável se o solo estava compactado.

Os atributos físicos do solo avaliados (densidade do solo, microporosidade, macroporosidade e porosidade total) não diferiram entre as épocas de avaliação (Tabela 2). Portanto, pode-se inferir que não houve degradação física do solo após a entrada dos animais na área. Vários fatores levaram a estes resultados, como a baixa taxa de lotação utilizada e o período de pastejo ser realizado em época do ano com baixos índices de precipitação, o que torna o solo mais resistente à compactação (Ribeiro \& Souza, 2018). Aliado a isto, o sistema de rotação de culturas em plantio direto empregado na propriedade, com uso de diferentes espécies como milho, soja, feijão e algodão, nas quais apresentam diferenças no crescimento do sistema radicular e na produção de biomassa vegetal, proporcionam melhoria nas propriedades físicas e químicas de solo (Nunes et al., 2018).

Diferentemente das demais variáveis, a disponibilidade e a porcentagem de biomassa seca, além da cobertura do solo, foram influenciadas pelas épocas de avaliação (Figuras 2a, 2b e 3). A disponibilidade de biomassa seca da braquiária diminuiu até o início de setembro, com posterior aumento (Figura 2a). Comportamento semelhante foi observado para a biomassa seca total. Os decréscimos na produção e na porcentagem da biomassa seca da braquiária nas primeiras épocas de avaliação são atribuídos ao pastejo dos animais e às condições desfavoráveis ao crescimento da gramínea, como temperaturas amenas em relação ao período de verão, comum nessa época do

Tabela 2. Valores médios da densidade do solo, micro e macroporosidade, porosidade total e relação micro/ macroporosidade antes ( 26 de julho) e após a retirada dos animais (02 de novembro) da área experimental nas camadas de solo. Montividiu-GO.

\begin{tabular}{|c|c|c|c|}
\hline \multirow{2}{*}{ Camada (m) } & \multicolumn{2}{|c|}{ Épocas de avaliação } & \multirow{2}{*}{ Média } \\
\hline & 26 de julho & 02 de novembro & \\
\hline \multicolumn{4}{|c|}{--- Densidade $\left(\mathrm{Mg} \mathrm{m}^{-3}\right)$--- } \\
\hline 0,0 a 0,1 & $1,22 \pm 0,04$ & $1,25 \pm 0,05$ & 1,23 \\
\hline 0,1 a 0,2 & $1,27 \pm 0,03$ & $1,28 \pm 0,03$ & 1,27 \\
\hline 0,2 a 0,4 & $1,21 \pm 0,04$ & $1,29 \pm 0,04$ & 1,25 \\
\hline Médias & $1,23 \pm 0,04$ & $1,27 \pm 0,04$ & 1,25 \\
\hline \multicolumn{4}{|c|}{--- Microporosidade $\left(\mathrm{m}^{3} \mathrm{~m}^{-3}\right)---$} \\
\hline 0,0 a 0,1 & $0,32 \pm 0,01$ & $0,29 \pm 0,04$ & 0,30 \\
\hline 0,1 a 0,2 & $0,30 \pm 0,02$ & $0,26 \pm 0,03$ & 0,28 \\
\hline 0,2 a 0,4 & $0,27 \pm 0,01$ & $0,27 \pm 0,04$ & 0,27 \\
\hline Médias & $0,30 \pm 0,01$ & $0,27 \pm 0,04$ & 0,28 \\
\hline \multicolumn{4}{|c|}{--- Macroporosidade $\left(\mathrm{m}^{3} \mathrm{~m}^{-3}\right)$--- } \\
\hline 0,0 a 0,1 & $0,23 \pm 0,02^{*}$ & $0,20 \pm 0,03$ & 0,22 \\
\hline 0,1 a 0,2 & $0,24 \pm 0,02$ & $0,22 \pm 0,03$ & 0,23 \\
\hline 0,2 a 0,4 & $0,24 \pm 0,02$ & $0,25 \pm 0,02$ & 0,24 \\
\hline Médias & $0,24 \pm 0,02$ & $0,22 \pm 0,03$ & 0,23 \\
\hline \multicolumn{4}{|c|}{--- Porosidade total $\left(\mathrm{m}^{3} \mathrm{~m}^{-3}\right)---$} \\
\hline 0,0 a 0,1 & $0,55 \pm 0,04$ & $0,50 \pm 0,04$ & 0,52 \\
\hline 0,1 a 0,2 & $0,53 \pm 0,04$ & $0,49 \pm 0,04$ & 0,51 \\
\hline 0,2 a 0,4 & $0,52 \pm 0,04$ & $0,52 \pm 0,04$ & 0,52 \\
\hline Médias & $0,53 \pm 0,04$ & $0,50 \pm 0,04$ & 0,52 \\
\hline
\end{tabular}

*A sobreposição dos intervalos de confiança indica ausência de diferenças entre as médias ( $>00,05)$. 
ano, e a baixa disponibilidade de água no solo decorrente da escassez de chuvas (Figura 1).

O posterior acúmulo de biomassa seca de braquiária, mesmo sob condições de pastejo, é justificado pelas condições favoráveis ao crescimento com a ocorrência das primeiras chuvas (Figura 1). Também favoreceu para o crescimento das plantas de braquiária o aumento da temperatura média do ar, além da baixa taxa de lotação usada na área. Consequentemente, constatou-se aumento da disponibilidade de biomassa seca total até o final do período de pastejo. Desta forma, além dos benefícios do consórcio de mi-
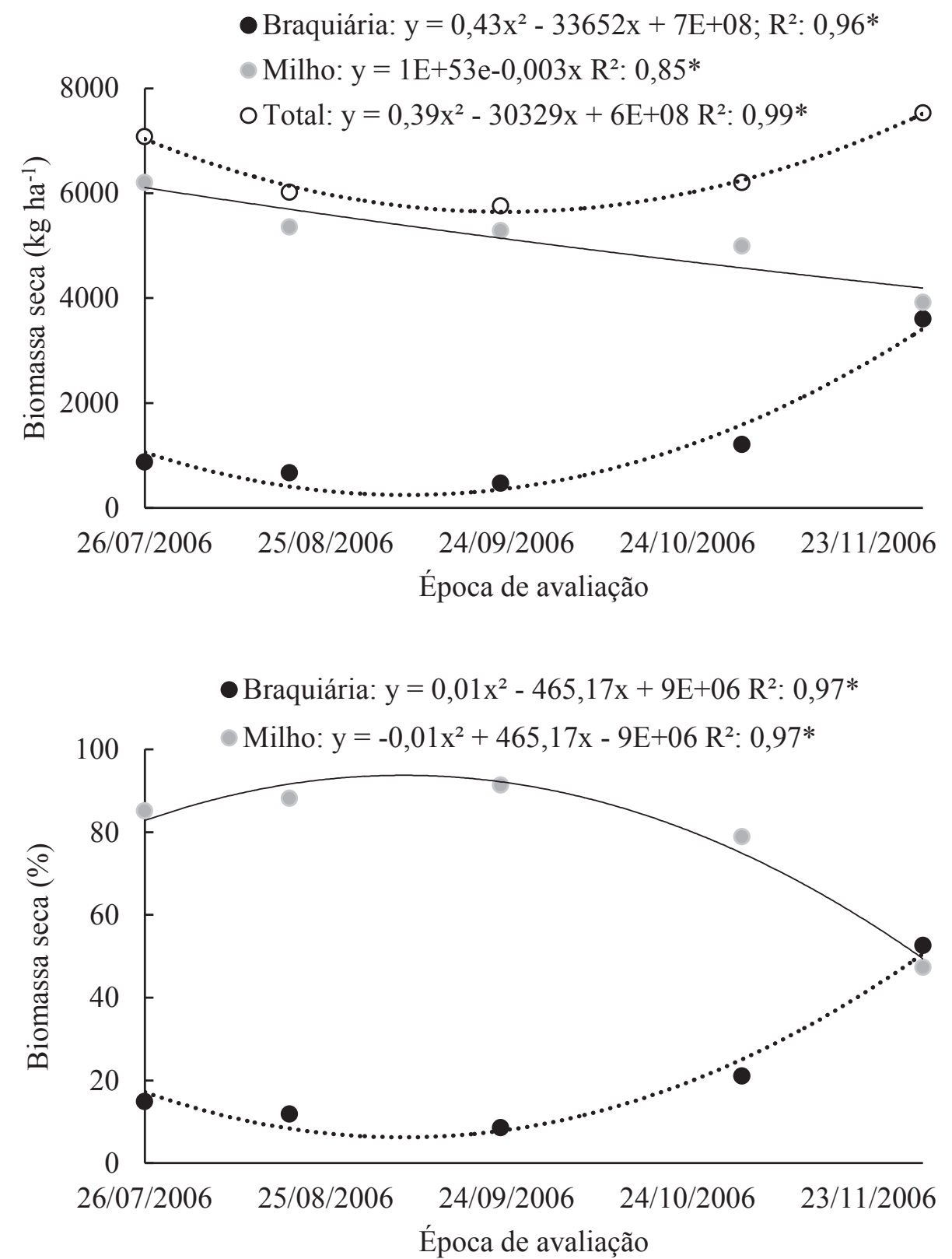

Figura 2. Biomassa seca de braquiária, do milho e total (a) e percentual da biomassa da palhada de braquiária e do milho (b) nas épocas de avaliação. Montividiu-GO, 2006. 
lho+braquiária na safrinha para o SILP relacionados à conservação do solo e a oferta de forragem animal, a biomassa de braquiária depois de mineralizada contribui para aumentos do teor de nitrogênio nas culturas subsequentes (Oliveira et al., 2017), como soja e trigo (Crusciol et al., 2015).

É interessante frisar que a porcentagem de palhada de milho apresentou acréscimos até 28 de agosto (33 dias após o início das avaliações) (Figura 2b). Isto é atribuído ao pastejo dos animais alimentando em maior proporção de braquiária. Consequentemente, há redução na proporção da biomassa da braquiária e aumento da proporção do milho. Com o início do período chuvoso esta relação se inverte. A partir deste momento, pode-se notar que a produção de biomassa da braquiária compensa a redução da biomassa do milho. Este efeito compensatório auxilia a manutenção da palhada para o sistema plantio direto, contribuindo para a manutenção da qualidade física do solo nos sistemas de produção agrícola da região.

Na última avaliação (02 de dezembro), a quantidade de biomassa seca total atingiu aproximadamente $7.500 \mathrm{~kg} \mathrm{ha}^{-1}$ (Figura 2a). Esta quantidade de palhada produzida nas condições do Centro-Oeste, principalmente quando se usa a Brachiaria brizantha, é fundamental para a proteção do solo contra erosão, para a manutenção da umidade do solo em períodos de menor ocorrência de precipitação, e também para o manejo das plantas daninhas na cultura sucessora, ou seja, na safra de algodão de verão (Ikeda et al., 2007). Destaca-se também que na referida época de avaliação, constatou-se maior percentual de biomassa de braquiária em relação à de milho.

A importância dos SILP está também no fato de que as biomassas do milho e da braquiária proporcionavam, aproximadamente, 93\% de cobertura do solo na colheita do cereal (primeira época de avalia- ção) (Figura 3). Devido à decomposição da palhada de milho, que estava em maior proporção em relação a da braquiária nas primeiras avaliações, o valor de cobertura de solo diminuiu até 27 de agosto (32 dias após o início das avaliações). Posteriormente, como relatado anteriormente, houve retomada do crescimento da braquiária, o que fez a cobertura do solo atingir $100 \%$ ao final do período de avaliação (02 de dezembro). A plena cobertura do solo, como observado no trabalho, contribui efetivamente para a maior proteção do solo contra a insolação e o impacto das gotas da chuva e, preservando a matéria orgânica, resultando em redução na evaporação de água do solo e na erosão (Chioderoli et al., 2010). Esses resultados corroboram com os observados por Chioderoli et al. (2010) que enfatizam a importância do consórcio de milho+braquiária para proporcionar adequada cobertura do solo e produção de biomassa seca total, essencial para a manutenção e longevidade do sistema de plantio direto.

A análise da relação $\mathrm{C} / \mathrm{N}$ permitiu constatar alto valor para ambas as culturas avaliadas, com destaque para o milho que apresentou maior relação $\mathrm{C} / \mathrm{N}$ em relação a da braquiária em todas as épocas de avaliação (Tabela 3). Este resultado é justificado pelo fato da planta de milho apresentar maior proporção de material lignificado, como colmos e sabugos, e por se tratar de tecido morto, parcialmente mineralizado, e não em fase de crescimento, como foi a da braquiária.

Sendo assim, nota-se que a utilização do consórcio milho+braquiária na safrinha proporciona benefícios para os sistemas agrícolas do Centro-Oeste do Brasil. Além de permitir a atividade pecuária (terceira safra), com a engorda dos animais e sem causar impactos negativos ao solo, o sistema em questão proporcionou uma excelente cobertura do solo e a produção de matéria seca de alta relação $\mathrm{C} / \mathrm{N}$. Isto 


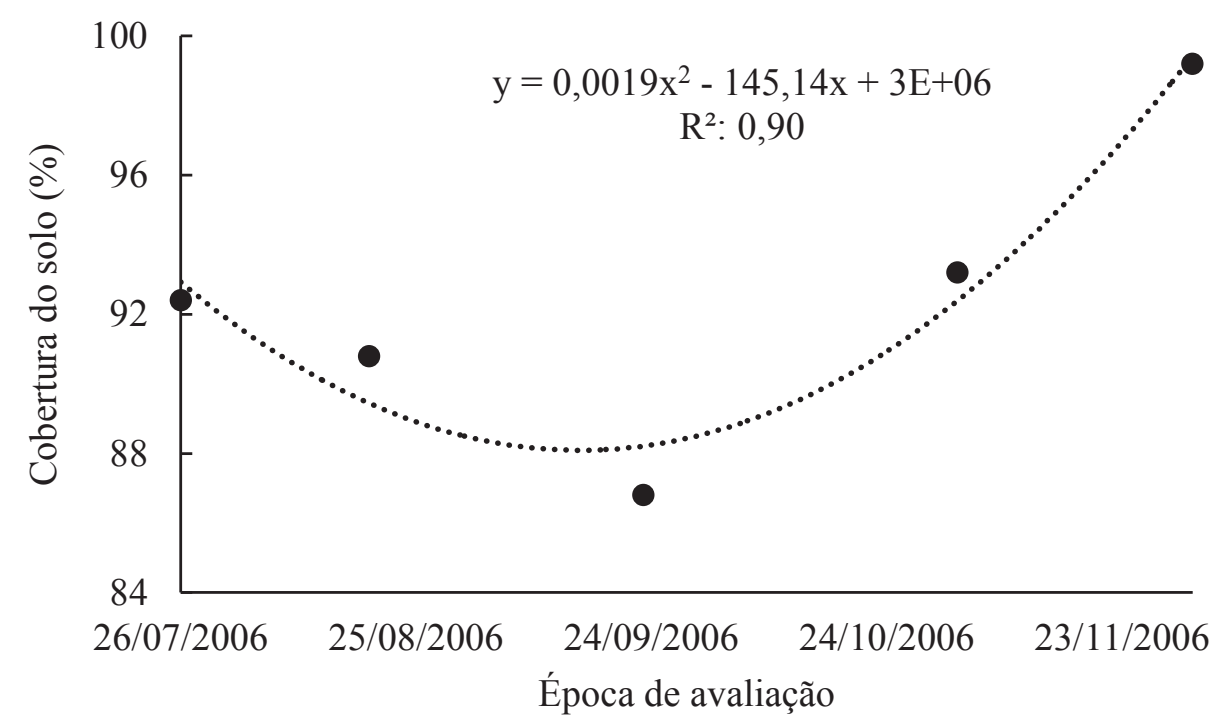

Figura 3. Percentual de cobertura do solo das palhadas da braquiária e do milho nas épocas de avaliação. Montividiu-GO, 2006.

Tabela 3. Teores de $\mathrm{N}$ e $\mathrm{C}$ e valores médios da relação $\mathrm{C} / \mathrm{N}$ no milho e na braquiária em função das épocas de avaliação, Montividiu-GO.

\section{Épocas de avaliação}

\begin{tabular}{|c|c|c|c|c|c|c|c|c|}
\hline & \multicolumn{2}{|c|}{26 de julho } & \multicolumn{2}{|c|}{23 de setembro } & \multicolumn{2}{|c|}{02 de novembro } & \multicolumn{2}{|c|}{02 de dezembro } \\
\hline & Milho & Braquiária & Milho & Braquiária & Milho & Braquiária & Milho & Braquiária \\
\hline & \multicolumn{8}{|c|}{--- Teores $\left(\mathrm{g} \mathrm{kg}^{-1}\right)$--- } \\
\hline $\mathrm{N}$ & 8,90 & 12,10 & 7,90 & 11,70 & 8,40 & 12,40 & 7,90 & 12,30 \\
\hline C & 414,97 & 483,06 & 418,31 & 474,43 & 418,33 & 491,41 & 424,47 & 466,57 \\
\hline & \multicolumn{8}{|c|}{--- Relação C/N --- } \\
\hline & $47,35 \pm 1,12^{*}$ & $42,18 \pm 0,78$ & $54,32 \pm 3,22$ & $41,30 \pm 2,57$ & $49,99 \pm 2,01$ & $41,61 \pm 1,43$ & $55,34 \pm 3,58$ & $39,51 \pm 4,33$ \\
\hline
\end{tabular}

*A sobreposição dos intervalos de confiança indica ausência de diferenças entre as médias ( $\mathrm{p}>0,05)$.

faz com que a decomposição da biomassa seja mais lenta após sua dessecação para implantação da cultura sucessora no verão. Estes resultados tornam-se importantes para a região de estudo, pois as condições climáticas nesse período dificultam a manutenção da palhada na superfície do solo nas propriedades que adotam o sistema plantio direto como manejo de solo para produção de grãos.

\section{Conclusões}

O sistema de integração lavoura-pecuária (SILP) permitiu a intensificação econômica da área com agregação de uma terceira safra de carne (ou de boi) ao mesmo tempo em que contribuiu para melhoria da qualidade do sistema de plantio direto mediante acréscimo de adequada cobertura vegetal do solo, mesmo sob condições de pastejo. 
O pisoteio ocasionado pelos animais em pastejo, com baixa taxa de lotação, não alteraram a qualidade física do solo na área do SILP.

\section{Agradecimentos}

À Agropecuária Peeters S/A, pelo auxílio na condução do experimento.

\section{Referências}

ALMEIDA, C. X. de; CENTURION, J. F.; JORGE, R. F.; BARBOSA, J. C.; ANDRIOLI, I. Funções de pedotransferência para a curva de resistência do solo à penetração. Revista Brasileira de Ciência do Solo, v. 36, n. 6, p. 1745-1755, 2012.

DOI: 10.1590/S0100-06832012000600008.

ASSIS, R. L.; TORMENA, C. A.; BRAZ, L. B. P.; TORREZAN, L. F. N.; CARGNELUTTI FILHO, A.; FERREIRA, C. J. B. Efeito do revolvimento e de sistemas de manejo na qualidade física do solo. In: CONGRESSO BRASILEIRO DE CIÊNCIA DO SOLO, 34., 2013, Florianópolis. Ciência do solo: para quê e para quem: anais. Florianópolis: Sociedade Brasileira de Ciência do Solo, 2013.

BELONI, T.; PIOTTO, V. C.; MARI, G. C.; PINHEIRO, A. A.; TORMENA, C. A.; CECATO, U. Root system and resistance to penetration of Mombaça grass fertilized with nitrogen and irrigated. Semina: Ciências Agrárias, v. 37, n. 5, p. 3243-3252, 2016. DOI: $10.5433 / 1679-0359.2016 v 37 n 5 p 3243$.

CANESIN, R. C.; BERCHIELLI, T. T.; ANDRADE, P.; REIS, R. A. Desempenho de bovinos de corte mantidos em pastagem de capim-marandu submetidos a diferentes estratégias de suplementação no período das águas e da seca. Revista Brasileira de Zootecnia, v. 36, n. 2, p. 411420, 2007. DOI: 10.1590/S1516-35982007000200019.

CHIODEROLI, C. A.; MELLO, L. M. M.; GRIGOLLI, P. J.; SILVA, J. O. R.; CESARIN, A. L. Consorciação de braquiárias com milho outonal em plantio direto sob pivô central. Engenharia Agrícola, v. 30, n. 6, p. 1101-1109, 2010. DOI: $10.1590 / \mathrm{S} 0100-69162010000600011$.

CRUSCIOL, C. A. C.; NASCENTE, A. S.; BORGHI, E.; SORATTO, R. P.; MARTINS, P. O. Improving soil fertility and crop yield in a tropical region with palisadegrass cover crops. Agronomy Journal, v. 107, n. 6, p. 2271-2280, 2015. DOI: 10.2134/agronj14.0603.

DONAGEMA, G. K.; CAMPOS, D. V. B. de; CALDERANO, S. B.; TEIXEIRA, W. G.; VIANA, J. H. M. (Org.). Manual de métodos de análise de solo. 2. ed. rev. Rio de Janeiro: Embrapa Solos, 2011. 230 p. (Embrapa Solos. Documentos, 132).

FERREIRA, C. J. B.; TORMENA, C. A.; CECATO, U.; FRANCO, H. H. S.; MOREIRA, W. H.; GALBEIRO, S.; RIBEIRO, O. L. Soil physical properties under a 'Tanzânia' grass pasture fertilized with mineral nitrogen or intercropped with stylosanthes. Pesquisa Agropecuária Brasileira, v. 53, n. 4, p. 478-486, 2018.

DOI: $10.1590 / \mathrm{s} 0100-204 \times 2018000400009$.

FERREIRA, R. R. M.; TAVARES FILHO, J.; FERREIRA, V. M. Efeitos de sistemas de manejo de pastagens nas propriedades físicas do solo. Semina: Ciências Agrárias, v. 31, n. 4, p. 913-932, 2010.

FIDALSKI, J.; TORMENA, C. A.; ALVES, S. J. Intervalo hídrico ótimo de um Latossolo Vermelho distrófico, após o primeiro período de pastejo contínuo de Brachiaria ruziziensis, em sistema integração lavoura-pecuária. Revista Brasileira de Ciência do Solo, v. 37, n. 3, p. 775-783,2013. DOI: 10.1590/S0100-06832013000300024.

FLÁVIO NETO, J.; SEVERIANO, E. C.; COSTA, K. A. P.; GUIMARÃES JUNNYOR, W. S.; GONÇALVES, W. G.; ANDRADE, R. Biological soil loosening by grasses from genus Brachiaria in crop-livestock integration. Acta Scientiarum.Agronomy, v. 37, n. 3, p. 375-383, 2015. DOI: 10.4025/actasciagron.v37i3.19392.

IKEDA, F. S.; MITJA, D.; VILELA, L.; CARMONA, R. Banco de sementes no solo em sistemas de cultivo lavoura- 
pastagem. Pesquisa Agropecuária Brasileira, v. 42, n. 11, p. 1145-1151, 2007.

DOI: 10.1590/S0100-204X2007001100005.

IMHOFF, S.; SILVA, A. P.; TORMENA, C. A. Aplicações da curva de resistência no controle da qualidade física de um solo sob pastagem. Pesquisa Agropecuária Brasileira, v. 35, n. 7, p. 1493-1500, 2000.

DOI: 10.1590/S0100-204X2000000700025.

MAIA, G. A.; COSTA, K. A. P.; SEVERIANO, E. C.; EPIFANIO, P. S.; FLÁVIO NETO, J.; RIBEIRO, M. G. Yield and chemical composition of brachiaria forage grasses in the offseason after corn harvest. American Journal of Plant Science, v. 5, n. 7, p. 933-941, 2014. DOI: 10.4236/ajps.2014.57106.

MALAVOLTA, E.; VITTI, G. C.; OLIVEIRA, S. A. Avaliação do estado nutricional de plantas: princípios e aplicações. 2. ed. Piracicaba: Potafos, 1997. 319 p.

MOREIRA, W. H.; BETIOLI JUNIOR, E.; PETEAN, L. P.; TORMENA, C. A.; ALVES, S. J.; COSTA, M. A. T.; FRANCO, H. H. S. Atributos físicos de um Latossolo Vermelho distroférrico em sistema de integração lavoura pecuária. Revista Brasileira de Ciência do Solo, v. 36, n. 2, p. 389-400, 2012.

DOI: $10.1590 / \mathrm{S} 0100-06832012000200008$.

NUNES, M. R.; VAN ES, H. M.; SCHIN DELBECK, R.; RISTOW, A. J.; RYAN, M. No-till and cropping system diversification improve soil health and crop yield. Geoderma, v. 328, n. 1, p. 30-43, 2018.

DOI: 10.1016/j.geoderma.2018.04.031.

OLIVEIRA, S. M.; FAVARIN, J. L.; ALMEIDA, R. E. M. Nitrogênio no consórcio entre milho e braquiária. Foz do Iguaçu: Federação Brasileira de Plantio Direto e Irrigação, 2017.Disponível em: <https://febrapdp.org.br/ noticias/329/16O-encontro-nacional-de-plantio-diretovai-movimentar-a-capital-do-agronegOcio/nitrogenio-noconsorcio-entre-milho-e-braquiaria>. Acesso: 19 dez. 2018.
PAYTON, M. E.; MILLER, A. E.; RAUN, R. Testing statistical hypotheses using standard error bars and confidence intervals. Communications in Soil Science and Plant Analysis, v. 31, n. 5/6, p. 547-551, 2000. DOI: $10.1080 / 00103620009370458$.

PETEAN, L. P.; TORMENA, C. A.; ALVES, S. J. Intervalo hídrico ótimo de um Latossolo Vermelho distroférrico sob plantio direto em sistema de integração lavoura-pecuária. Revista Brasileira de Ciência do Solo, v. 34, n. 5, p. 15151526, 2010. DOI: 10.1590/S0100-06832010000500004.

PETTER, F. A.; PACHECO, L. P.; PROCÓPIO, S. O.; CARGNELUTTI FILHO, A.; VOLF, M. R. Seletividade de herbicidas à cultura do milho e ao capim-braquiária cultivadas no sistema de integração lavoura-pecuária. Semina: Ciências Agrárias, v. 32, n. 3, p. 855-864, 2011.

RIBEIRO, K. D.; SOUZA, L. K. Limites de Atterberg e sua correlação com a granulometria e matéria orgânica dos solos. Brazilian Journal of Biosystems Engineering, v. 12, n. 2, p. 185-196, 2018.

DOI: 10.18011/bioeng2018v12n2p185-196.

SANTOS, H. G. dos; JACOMINE, P. K. T.; ANJOS, L. H. C. dos; OLIVEIRA, V. A. de; LUMBRERAS, J. F.; COELHO, M. R.; ALMEIDA, J. A. de; ARAÚJO FILHO, J. C. de; OLIVEIRA, J. B. de; CUNHA, T. J. F. Sistema Brasileiro de Classificação de Solos. 5. ed. rev. e ampl. Brasília, DF: Embrapa, 2018. 306 p.

STOLF, R. Teoria e teste experimental de fórmulas de transformação dos dados de penetrômetro de impacto em resistência do solo. Revista Brasileira de Ciência do Solo, v. 15, n. 1, p. 229-235, 1991.

VEIGA, M.; BALBINOT JÚNIOR, A. A.; OLIVEIRA, D. A. Soil physical attributes in forms of sowing the annual winter pasture and intervals between grazing. Revista Ciência Agronômica, v. 45, n. 5, p. 896-905, 2014. Número especial.

DOI: $10.1590 /$ S1806-66902014000500005. 